\title{
Hepatopulmonary syndrome associated with schistosomal liver disease
}

\author{
Mohamed Al-Moamary MRCP, Ibrahim Altraif MRCP(UK)
}

\begin{abstract}
M Al-Moamary, I Altraif. Hepatopulmonary syndrome associated with schistosomal liver disease. Can J Gastroenterol 1997;11(5):449-450. A 55-year-old man with schistosomal liver disease presented with shortness of breath, orthodeoxia, platypnea, cyanosis, marked digital clubbing and liver failure. Extensive investigation revealed no other etiology for liver disease apart from schistosomiases. The diagnosis of hepatopulmonary syndrome was based on clinical grounds, as well as abnormal arterial blood gases and positive contrast echocardiography. The patient underwent orthotopic liver transplantation, which was initially successful, but then died of respiratory complications and multi-organ failure on day 42 post-transplant. To the authors' knowledge this is the first report of hepatopulmonary syndrome associated with schistosomal liver disease.
\end{abstract}

Key Words: Hepatopulmonary syndrome, Schistosomal liver disease

\section{Syndrome hépato-pulmonaire associé à la} maladie hépatique schistosomique

RÉSUMÉ : Un homme de 55 ans atteint de maladie hépatique schistosomique se présente pour essoufflement, hypoxémie orthostatique, dyspnée orthostatique, cyanose, hippocratisme marqué et insuffisance hépatique. L'examen approfondi n'a révélé aucune autre étiologie de la maladie hépatique que la schistosomiase. Le diagnostic de syndrome hépato-pulmonaire a été établi sur la base des signes cliniques, des gaz artériels anormaux et d'une échocardiographie de contraste positive. Le patient a subi une transplantation hépatique orthotopique qui a été couronnée de succès au début, mais le patient est décédé de complications respiratoires et d'insuffisance pluri-organique 42 jours après la transplantation. À la connaissance des auteurs, il s'agit du premier rapport de syndrome hépato-pulmonaire associé à une maladie hépatique schistosomique.
$\mathrm{H}$ epatopulmonary syndrome (HPS) is the triad of chronic liver dysfunction, abnormal arterial oxygenation and pulmonary vascular shunting (1). It is estimated to occur in $8 \%$ to $25 \%$ of liver transplant candidates (2-9). There are no reports of HPS associated with schistosomal liver disease in the literature. We report the first such case of HPS complicating schistosomal liver disease.

\section{CASE PRESENTATION}

A 55-year-old man known to have biopsy-proven hepatic fibrosis secondary to previously treated schistosoma mansonirelated liver disease. He presented in 1988 with hypersplenism for which he underwent splenectomy. In the summer of 1994 he developed dyspnea on minimal exertion, platypnea, dry cough and cyanosis upon standing. He was maintained on diuretics, and lactulose for increasing ascites and encephalopathy.

Physical examination revealed a thin, afebrile man with stable hemodynamic status, jaundice, cyanosis with stigmata of chronic liver disease and marked digital clubbing. His chest had bilateral basal lung crackles. He had previous splenectomy and moderate ascites.

Complete blood cell count was normal with hemoglobin of $130 \mathrm{~g} / \mathrm{L}$. Bilirubin was $98 \mu \mathrm{mol} / \mathrm{L}$ (normal 0 to 17 ) and albumin was $11 \mathrm{~g} / \mathrm{L}$ (38 to 50). Aspartate aminotransferase was $132 \mathrm{IU} / \mathrm{L}$ (normal 15 to 37), alanine aminotransferase 67 IU/L (30 to 65 ) and alkaline phosphates $243 \mathrm{IU} / \mathrm{L}$ (50 to 136 ). Hepatitis B and C serology was negative. Antinuclear antibody level was less than 40, and ceruloplasmin, iron studies and alpha 1 antitrypsin levels were normal. Endoscopic ret-

Department of Medicine, Department of Hepatobiliary Sciences, King Fahad National Guard Hospital, Riyadh, Kingdom of Saudi Arabia

Correspondence and reprints: Dr I Altraif, Consultant Hepatologist and Transplant Physician, Department of Hepatobiliary Sciences, King Fahad National Guard Hospital, PO Box 22490, Riyadh 11426, Kingdom of Saudi Arabia. Telephone 966-1-252-0088 ext 2314, fax 966-1-252-0438

Received for publication March 11, 1996. Accepted March 24, 1997 
TABLE 1

Arterial blood gas results

\begin{tabular}{lccc}
\hline \multirow{2}{*}{ Parameter } & \multicolumn{2}{c}{ Room air } & $\begin{array}{c}\mathbf{1 0 0 \%} \\
\text { oxygen }\end{array}$ \\
\hline $\mathrm{pH}$ & 7.4 & 7.44 & 7.47 \\
$\mathrm{PaCO}_{2}$ & 30 & 30 & 28 \\
$\mathrm{PaO}_{2}$ & 61 & 51 & 131 \\
Bicarbonate & 20 & 20 & 20 \\
Oxygen saturation & $93 \%$ & $88 \%$ & $98 \%$ \\
Arterial-alveolar difference & 48 & - & 540 \\
\hline
\end{tabular}

rograde cholangiopancreatography was consistent with cirrhosis, and the antimitochondrial antibody was negative. International normalized ratio was 2.8. grade II esophageal varices were documented by upper gastrointestinal endoscopy. Arterial blood gases (Table 1) revealed chronic respiratory alkalosis, hypoxemia, orthodeoxia and slight correction of hypoxemia on $100 \%$ inspired oxygen using a face mask technique. The estimated fraction of the intrapulmonary shunt from the nomogram was $35 \%$. Chest $\mathrm{x}$-ray was unremarkable. Forced expiratory volume in $1 \mathrm{~s}$ was $2.38(66 \%)$, forced vital capacity $2.08(71 \%)$ with a ratio of $87 \%$, total lung capacity 4.01 (67\%) and diffusion capacity 4.09 (48\%), which was consistent with moderate diffusion impairment.

Echocardiogram documented the intrapulmonary shunt by positive microbubbles test (microbubbles were seen in the right ventricle after four to five beats). Swan-Ganz catheterization study showed normal right ventricle and pulmonary artery pressures (right atrial pressure $1 \mathrm{mmHg}$, right ventricle pressure $17 / 1 \mathrm{mmHg}$, pulmonary artery pressure $16 / 1 \mathrm{mmHg}$ and pulmonary capillary wedge pressure $7 \mathrm{mmHg}$ ).

The patient underwent orthotropic liver transplantation because he was progressively symptomatic and had liver failure with worsening hypoxemia. The initial postliver transplant course showed gradual improvement in oxygenation. On the ninth post-transplantation day he was successfully extubated and maintained on $2 \mathrm{~L} / \mathrm{min}$ oxygen with a saturation of $94 \%$ to $96 \%$.

Eleven days after transplantation, bilateral lung infiltrates developed with shortness of breath and desaturation, for which he was reintubated. His sputum grew Actinobacter species and Klebsiella pneumoniae. Despite appropriate antibiotic coverage he continued to require a high fraction of inspired oxygen; for several days he was maintained on $100 \%$ oxygen. On day 42 post-liver transplant the patient died from severe hypoxemia, sepsis and multi-organ failure.

\section{DISCUSSION}

For the past four decades attention has focused on the association of oxygen desaturation with chronic liver disease. HPS was first suggested in 1977 by Kennedy and Knudson (3). It was proposed to be due to a remarkable dilation of the peripheral branches of the pulmonary vessels, reflecting a state of vasoparalysis to hypoxic stimuli. Direct arteriovenous communication has also been demonstrated $(4,5)$.
Various liver diseases have been associated with this syndrome, and the presence of intrapulmonary shunt has been shown to occur in schistosomal cor pulmonale without liver failure (6). To our knowledge this is the first report of HPS associated with liver failure due to schistosomal liver disease without cor pulmonale.

Clinically the combination of platypnea, digital clubbing and spider angioma in the setting of chronic liver disease is suggestive of HPS. This should be supported by the presence of hypoxemia and orthodeoxia, a decrease of the partial arterial oxygen concentration by $10 \%$ upon standing (7).

It is essential to establish the diagnosis of HPS. For practical purposes, contrast enhanced echocardiogram appears to be the most sensitive diagnostic test to detect intrapulmonary vascular dilation. ${ }^{99} \mathrm{Tc}$ microaggregated albumin scan and pulmonary angiography might be needed to confirm the diagnosis in certain cases (7-9).

The mechanism of HPS in schistosomal liver disease is probably not different from other etiologies of chronic liver dysfunction associated with HPS, but this is speculative because the mechanism of HPS is unknown. Until recently HPS was considered a contraindication for liver transplantation. However, the accumulated data have shown that HPS does not contraindicate surgery as long as intra- and postoperative oxygenation is maintained. Furthermore, severe hypoxemia has been proposed as an indication for liver transplantation (9). Krowka and Cortese (9) showed that 13 of 15 cases with HPS were transplanted successfully, and two of 15 cases had the procedure mainly for severe oxygen desaturation. This review showed resolution of hypoxemia in all but one patient who required arterial embolization.

In the case presented, severe hypoxemia was associated with HPS in a patient with schistosomal liver disease. This case demonstrates that schistosomiasis can be associated with HPS.

ACKNOWLEDGEMENTS: We thank Dr Sulaiman Al Majed for his critical comments, and Kay Finley and Jill Taylor for their expertise in typing the manuscript.

\section{REFERENCES}

1. Krowka MJ. Hepatopulmonary syndrome. Transplant Proc 1990;25:1746-7.

2. Hourani JM, Bellamy PE, Tashkin DP, et al. Pulmonary dysfunction in advanced liver disease: frequent occurrence of an abnormal diffusing capacity. Am J Med 1991;90:693-700.

3. Kennedy TC, Knudson RJ. Exercise-aggravated hypoxemia and orthodeoxia in cirrhosis. Chest 1977;72:305-9.

4. Agusti AGN, Roca J, Bosch J, et al. The lung in patients with cirrhosis. J Hepatol 1990;10:251-7.

5. Rodríguez-Roisin R, Agustí AG, Roca J, et al. The hepatopulmonary syndrome: New name and old complexities. Thorax 1992;47:897-902.

6. Rafla S, Sourour S. Detection of intrapulmonary shunt in schistosomal cor pulmonale. Chest 1993;104:1280-1.

7. Krowka MJ, Dickson ER, Cortese DA. Hepatopulmonary syndrome: Clinical observations and lack of therapeutics response to somatostatin analogue. Chest 1993;104:515-21.

8. Lange PA, Stoller JK. The hepatopulmonary syndrome. Ann Intern Med 1995;233:521-9.

9. Krowka MJ, Cortese D. Hepatopulmonary syndrome: Current concepts in diagnostic and therapeutics considerations. Chest 1994;105:1528-37. 


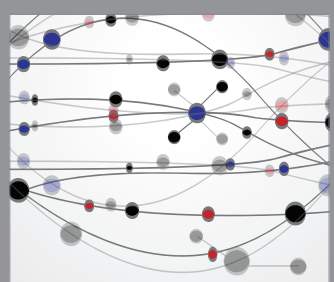

The Scientific World Journal
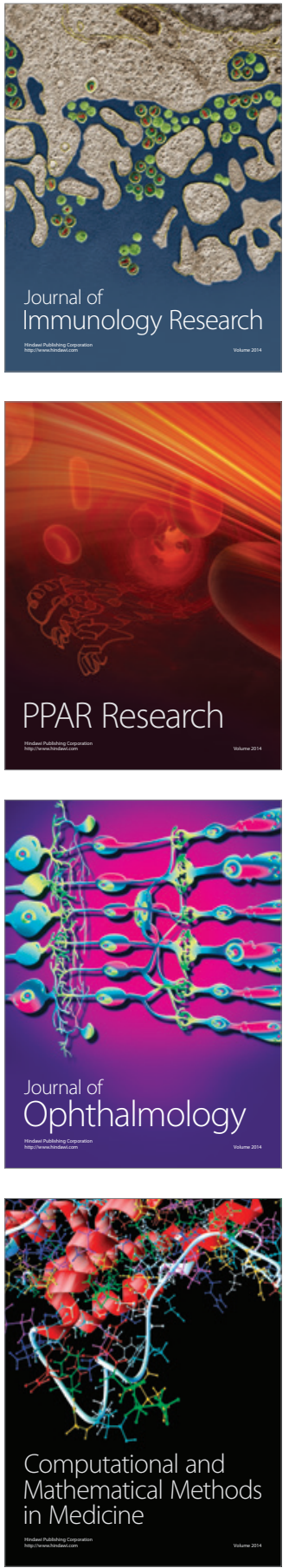

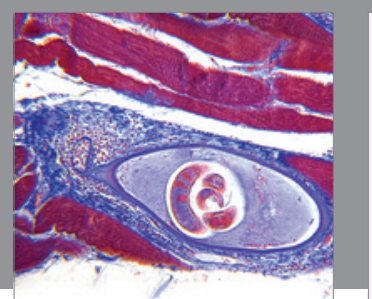

Gastroenterology Research and Practice

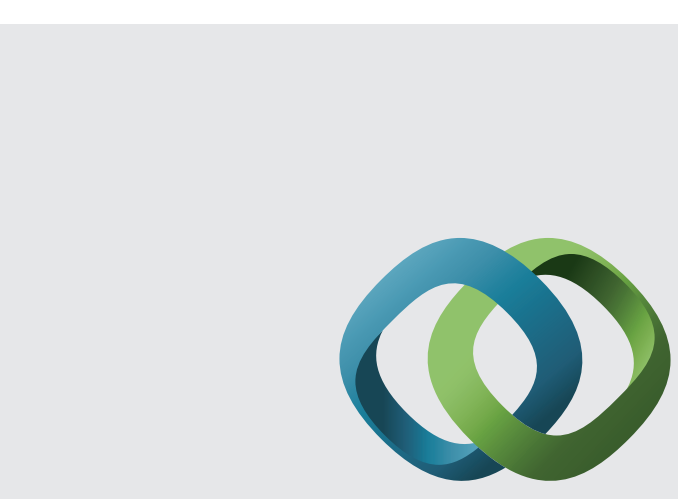

\section{Hindawi}

Submit your manuscripts at

http://www.hindawi.com
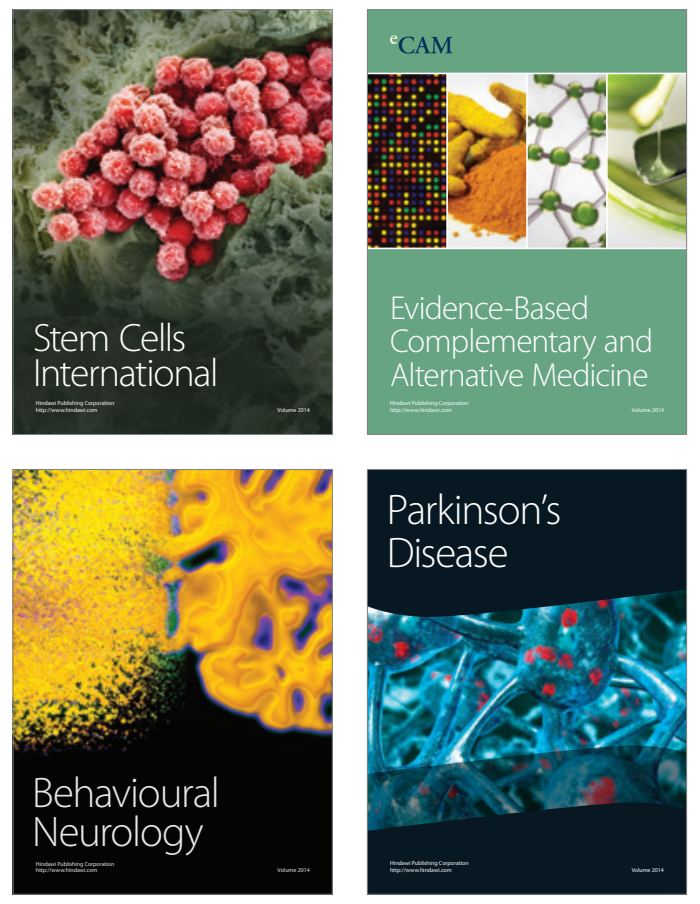
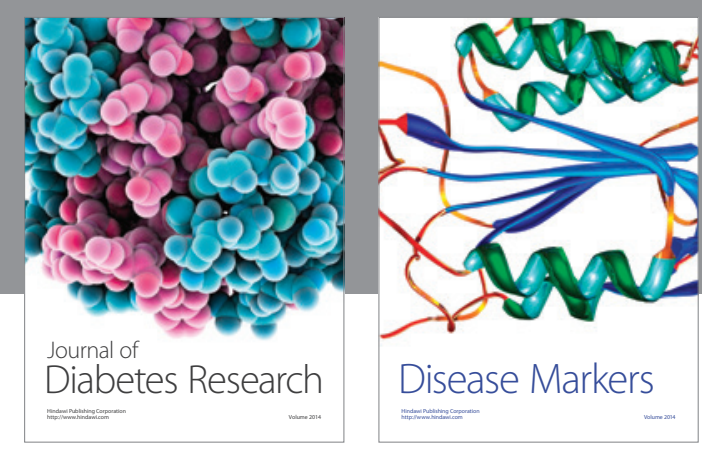

Disease Markers
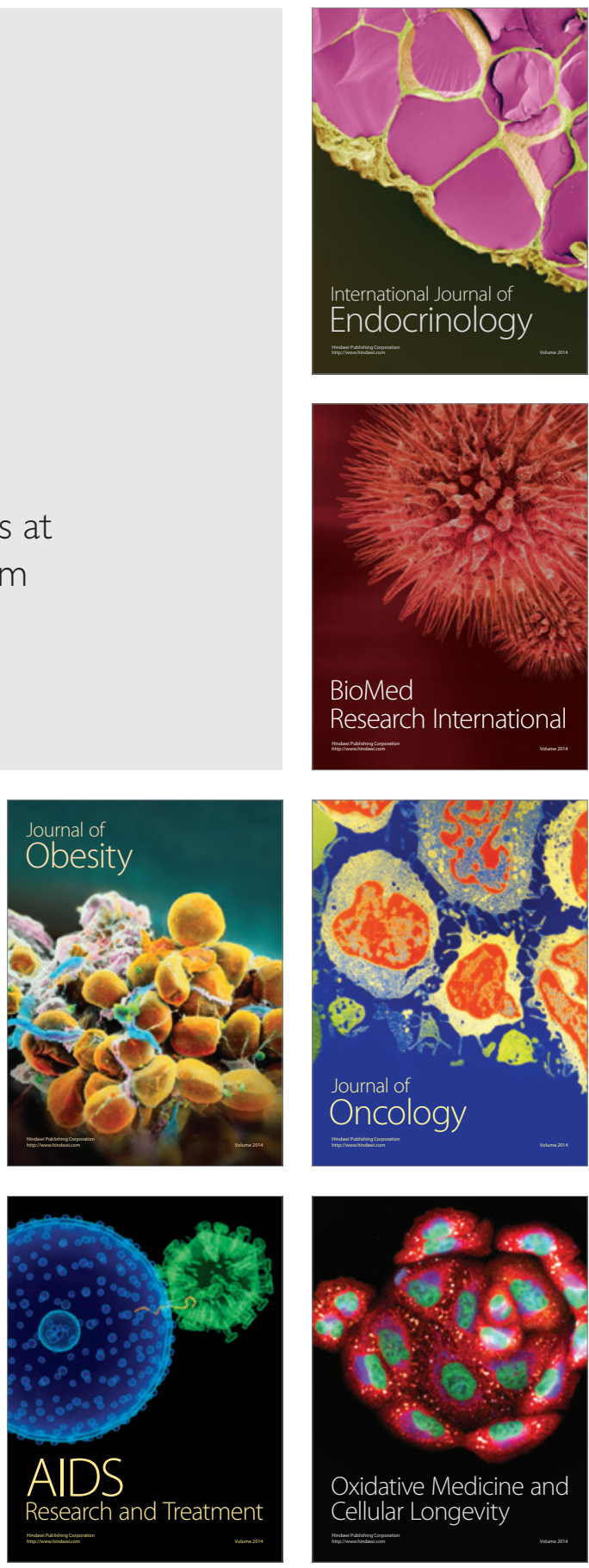